\title{
Research on Intracranial Pressure Changes of Craniocerebral Injury Caused by Cudgels
}

\author{
Hong-fa CHANG ${ }^{1,2}$, Zhen-jiang LIU ${ }^{1,2}$, Peng XIA ${ }^{1,2}$, Yong-min $\mathrm{YU}^{1,2}$, \\ Dai-qin $\mathrm{TAO}^{1,2}$ and Hong-wei $\mathrm{LI}^{1,2, \mathrm{a}, *}$ \\ ${ }^{1}$ Chongqing Engineering Research Center for Criminal Investigation Technology, \\ Chongqing 400707, China. \\ ${ }^{2}$ Institute of Forensic Science, Chongqing Public Security Bureau, Chongqing 400707, \\ China.3List all distinct addresses in the same way \\ a94582888@qq.com \\ ${ }^{*}$ Corresponding author
}

Keywords: Forensic pathology, Craniocerebral injury, Encephalic pressure, Cudgel.

\begin{abstract}
Objective To research intracranial pressure change rules of craniocerebral injury through experimentation on animals. Method According to the difference of the hit parts, the animals are divided into three groups to collect the intracranial pressure changes through data collection system and pressure sensor when craniocerebral injuries happen. Result In the top hit, occipitalia pressure value is positive and the pressure value of Encephalic tempus is positive too; in the tempus hit, occipitalia pressure value is positive, side-tempus pressure value is negative and top pressure value is positive. The pressure variation trend of the collected figure of the occipitalia hit group is different from that of the top hit group. Conclusion Different parts of the craniocerebral injury lead to the different intracranial pressure changes, and also the difference of the Mechanism of craniocerebral injury.
\end{abstract}

\section{Introduction}

Traumatic craniocerebral injury is one of the important reasons that lead to death and perpetual dysfunction [1], and at the same time, a club is usually used as one of the violence assault tools because it is easily available. Therefore, craniocerebral passivity injury is one of the common injuries that refers to personal disoperative in criminal cases [2]. Passivity attacking tools such as peelers, clubs are common. At present, analysis on forensic medicine characteristic of craniocerebral injury mainly depends on the long term work experience of the case-inspecting staff, which has large differences. Besides, the injury mechanism and the dose-effect relationship of craniocerebral injury still lack detail data and scientific rigorous analysis techniques and means.

In forensic practice, many scholars have correspondingly done a lot of researches on the physiology of craniocerebral injury to evaluate the attacking mechanism and modes [3]. And the research on intracranial pressure changes of craniocerebral injury has established certain basis for the research of the forming mechanism of craniocerebral injury [4].

To get a more particular knowledge of biomechanics response of the head under different types of hitting power, to have an intensive study on the characteristics of the injury and the forming mode mechanism, we must know biomechanics response of the head under external force. Therefore, we need to establish the dose-effect relationship 
between craniocerebral injury and club hitting power through experimentation on animals.

\section{Materials and Methods}

\section{Experimental Facilities}

1) BIM-II type biology striking machine and self-made striking head;

2) breathing machines for small animals (medical science instrument plant in Shanghai);

3) energy absorption material for buffering (sponge mat);

4) pressure sensor (CM-093-500 series, Bengbu Saiyingelectronic Technique Research Institution);

5) data collection system (Synergy data collection system, Hi-Tech formula of America);

6) dentistry Sander (Shanghai Maisen medical treatment Science and Technology Ltd);

7) dental base acrylic resin powder (Chongqing Donghua Dental Materials Plant).

\section{Experimental Animal and Grouping}

According to the different hit parts, thirty adult healthy large-eared New Zealand white rabbits (weight $2.2 \pm 0.2 \mathrm{~kg}$ ), male or female, offered by Third Military Medical University Field Operations Department of Surgery Research Institution Animal Experimental Center (Chongqing, China) are divided into the following groups:

1) Group One: peeler (15mm) top injury (10 rabbits);

2) Group Two: peeler (15mm) tempus injury (10 rabbits);

3) Group Three: peeler (15mm) occipitalia (10 rabbits).

\section{Parameter of Biology Striking Machine}

The twice striking hammer of the striking machine $1880 \mathrm{~g}$, weight of the striking heads, peeler $84.5 \mathrm{~g}$. This experiment aims to simulate raniocerebral injury model, the vulnerating air pressure of the striking machine $600 \mathrm{kpa} / \mathrm{cm} 2$, the decrement of the twice striking hammer is $10 \mathrm{~mm}$. The top hit place is sagittal axis in the center of the calvarium. To avoid the influence of the protruding eyeballs and auricles of the rabbit to the striking, the hit part of the tempus hit is between the eye sockets and the external auditory canals, and the included angle of the club and the horizontal position is $45^{\circ} \mathrm{C}$.

\section{Observation, Test Index and Operational Approach}

Make sure that the animals are fasting the night before the experiment and let them drink water routinely. Select the animals random, and select those that have no abnormalities through general observation. Mark on the aural regions and record their weights. Use "Fast to Sleep II" (0.1 0.15ml/kg) subcutaneous injection for anesthesia. After the anesthesia, get the preserved skin from the injured part. Let the rabbit lie on the side on the striking stage during the experiment, and make sure thatthe craniocerebral is in free state. Make the peeler get a parallel enfilade to the sagittal axis in the center of the calvarium. At the dead astern of the craniocerebral $10 \mathrm{~mm}$ away, we will place a sponge mat sized $18 \mathrm{~cm} * 18 \mathrm{~cm} * 20 \mathrm{~cm}$ for buffering to avoid secondary damage . Control the air pressure through air suction throttle. Use computer software system to do the vulnerating striking operation when the precision pressure gauge shows the wanted experimental assigned numerical value. The temperature of the laboratory maintains $25 \pm 5{ }^{\circ} \mathrm{C}$. 
Test of intracranial pressure: Analysis the pressure changes on the basis of data collection.

\section{Installation Site}

Occipitalia: deviation to right $2 \mathrm{~mm}$ of lambdoidal suture occipital protuberance.

Tempus: midpoint between eye socket and porus acusticus internus ligature.

Top: ligature ligature between sagittal axis and bilateral eye sockets fixed point (Figure 2).

Occipitalia hit: install 2 sensors at the top and left side tempus.

Tempus hit: install 3 sensors at the occipitalia, left side tempus and top.

Top: install 2 sensors at the top and left side tempus.

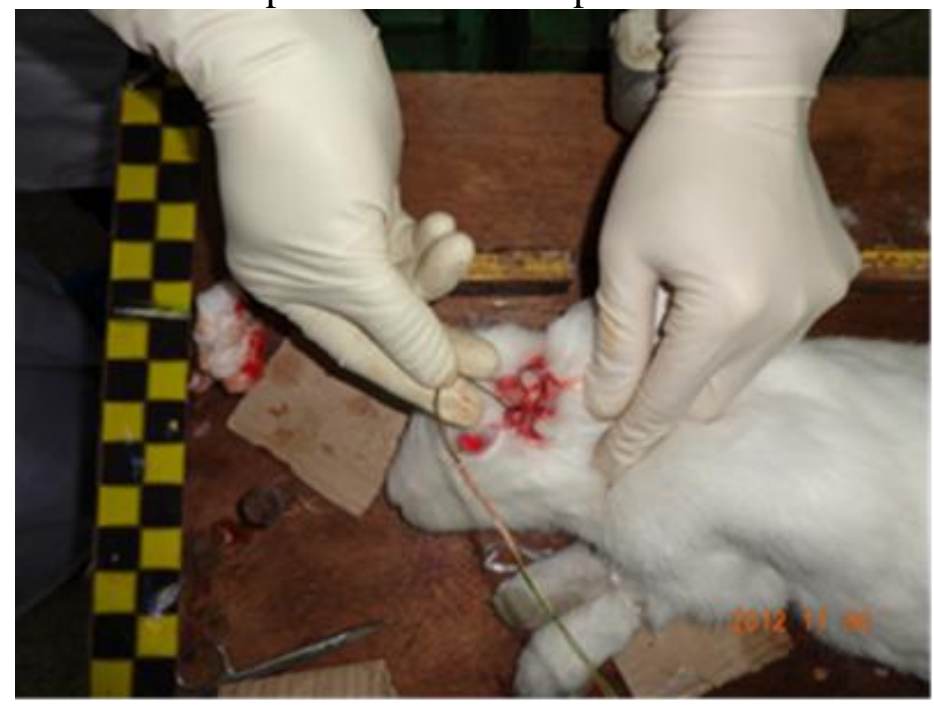

Fig.1 Installation site of tempus sensor

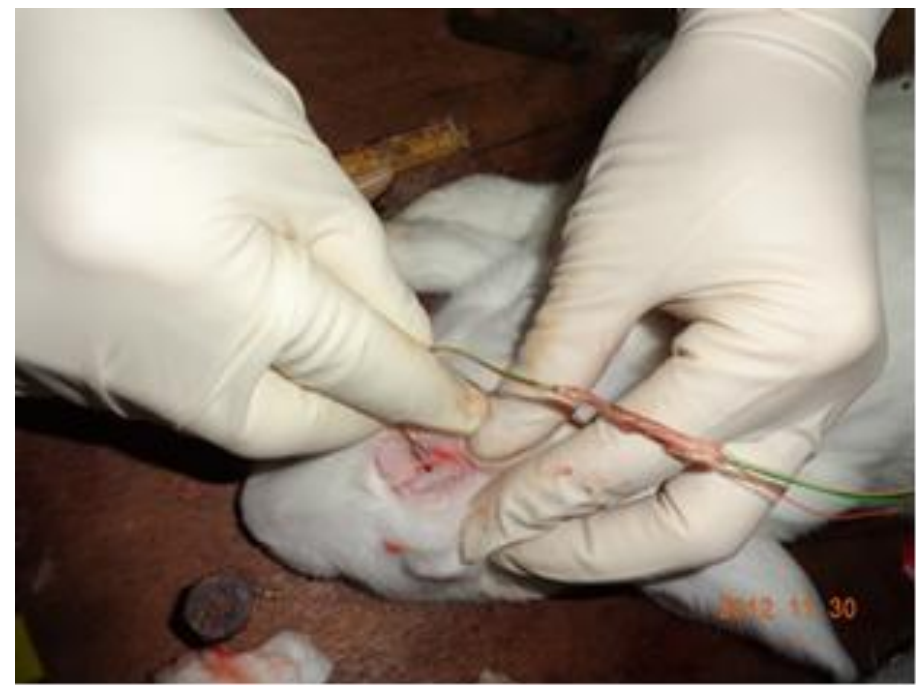

Fig.2 Installation site of top sensor

\section{Installation Method}

Methods of anesthesia are the same. After anesthesia the animals and trachea cannula are fastened to the headstock of the stereotaxis. Keep the left and right position and parietal bone anteroposterior position level. Preserve the skins and disinfect them at the corresponding position. Make a $1 \mathrm{~mm}$ notch and twin pole electric coagulation hemostasis. Stripping muscles and periosteum of passivity. Drill holes at the above 
positions, with diameter of $2.5 \mathrm{~mm}$. When there is sense of falling through, open endocranium carefully and place a pressure sensor head rapidly. And then smear some dental base acrylic resin powder on the gap between the bone window and the sensor head. Make the sensor rigorous and fixed. Suture the skin, and fix the connecting line of the sensor appropriately(Figure 3). Observe rabit $2 \mathrm{~h}$, and if there is no abnormalities, conduct bump test and pressure test.

\section{Data Collection System Debugging and Collecting Process}

Open data collection system, select recording gallery, adjust DC Bridge pattern, confirm energy grade and sensitivity coefficient isoparametric and trim automatically, select display mode and confirm start recorder.

Impact time-histories and strength oscilloscope are showed on the oscilloscope in millisecond (ms) and kilopascal (kpa) respectively. $\mathrm{X}$ axle is the impact time-histories $\mathrm{Y}$ axle is impact strength (Figure 4).

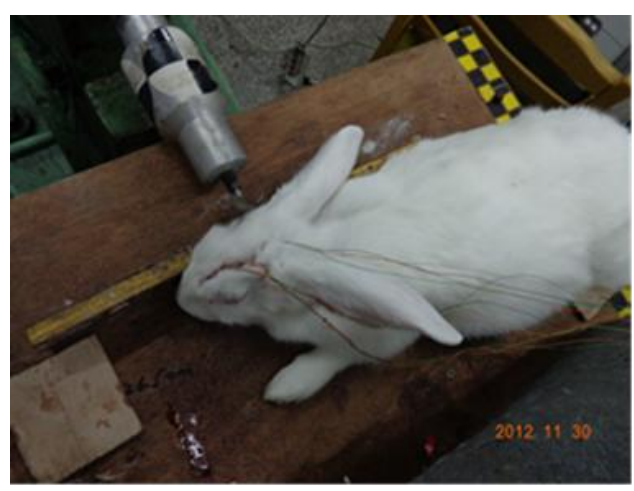

Fig.3 Sensor fixation

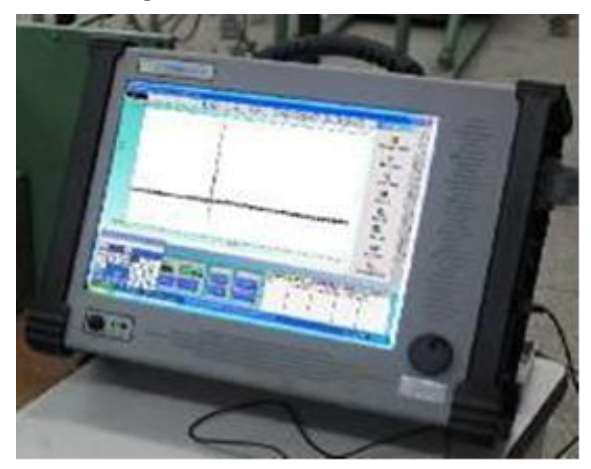

Fig.4 Data collection system

\section{Experimental Result}

As the conceptual data shows, in the top hit, occipitalia pressure is positive value and encephalic tempus pressure is positive value; in the tempus, occipitalia pressure is positive value, offside tempus pressure is negative and top pressure is positive value. The pressure variation trend of the occipitalia hit collection figure is the same as that of the top hit group. But from the point of view of the mean value and metrical data, the pressure value of every group varies (Table 1). 
Table 1 Test Result of Encephalic Pressure

\begin{tabular}{|c|c|c|c|c|c|c|c|}
\hline Groups & $\begin{array}{c}\text { Hitting } \\
\text { Parts }\end{array}$ & $\begin{array}{l}\text { Sensor } \\
\text { places }\end{array}$ & $\begin{array}{c}\text { Observed } \\
\text { Value(kpa) }\end{array}$ & $\begin{array}{l}\text { Sensor } \\
\text { places }\end{array}$ & $\begin{array}{c}\text { Observed } \\
\text { Value(kpa) }\end{array}$ & $\begin{array}{l}\text { Sensor } \\
\text { places }\end{array}$ & $\begin{array}{c}\text { Observed } \\
\text { Value(kpa) }\end{array}$ \\
\hline $\begin{array}{l}\text { crude } \\
\text { iron top } \\
550 \mathrm{kpa}\end{array}$ & top & occipitalia & 1613.015 & tempus & 1536.96 & & \\
\hline $\begin{array}{l}\text { crude } \\
\text { iron } \\
\text { temple } \\
550 \mathrm{kpa}\end{array}$ & tempus & top & 912.77 & occipitalia & 1253.01 & tempus & -168.555 \\
\hline $\begin{array}{l}\text { crude } \\
\text { iron } \\
\text { pillow } \\
550 \mathrm{kpa} \\
\end{array}$ & occipitalia & top & 1072.875 & tempus & 1166.095 & & \\
\hline
\end{tabular}

Figure 5 is top peeler hitting occipitalia collection figure. The moment after hitting, the pressure value goes up to the peak and then declines immediately and exceeds horizontal position and a negative value appears. The time of duration is extremely short and then reverts to horizontal position, but the location is under the level before hitting. Figure 6 is top peeler hitting tempus collection figure. The moment after hitting, the pressure value drops to a negative value and reaches the peak and then rises again. It continues for a long time and then reverts to the level before hitting little by little. Figure 7 is tempus peeler hitting offside tempus collection figure. The moment after hitting, the pressure peak value is negative and then turns into positive value. At the declining branch, it turns into positive and then reverts to the level before hitting.

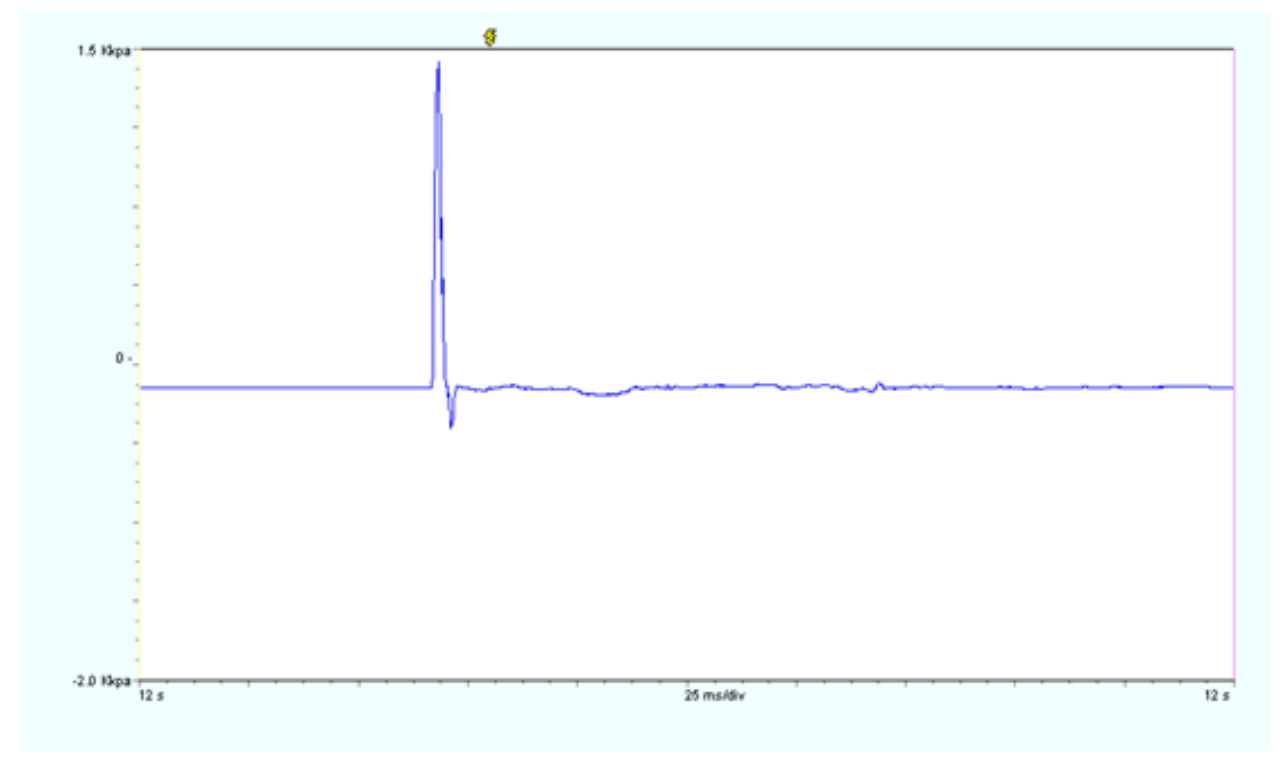

Fig.5 Occipitalia collection after hit by a peeler in the harnpan top 


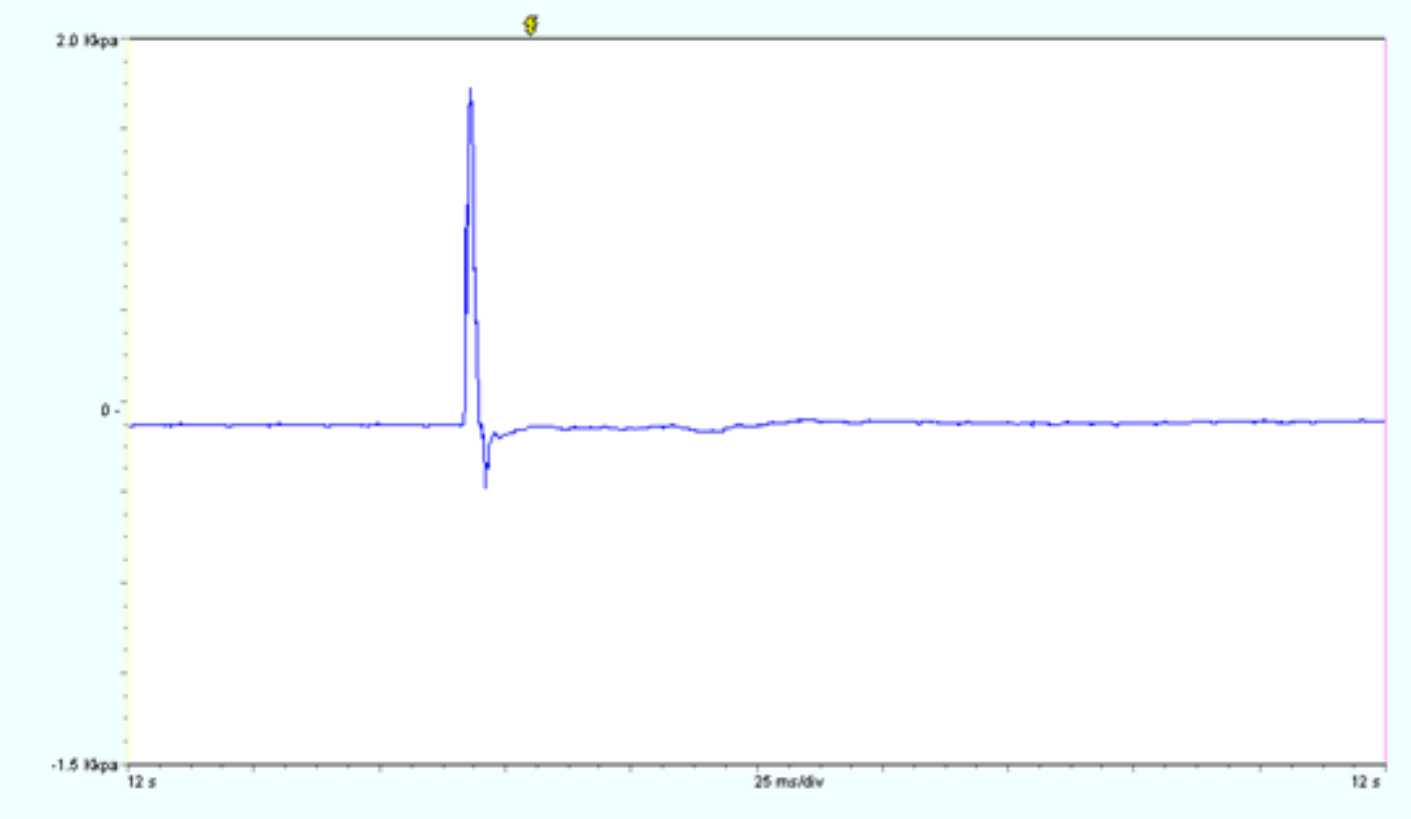

Fig.6 Tempus collection after hit by a peeler in the harnpan top

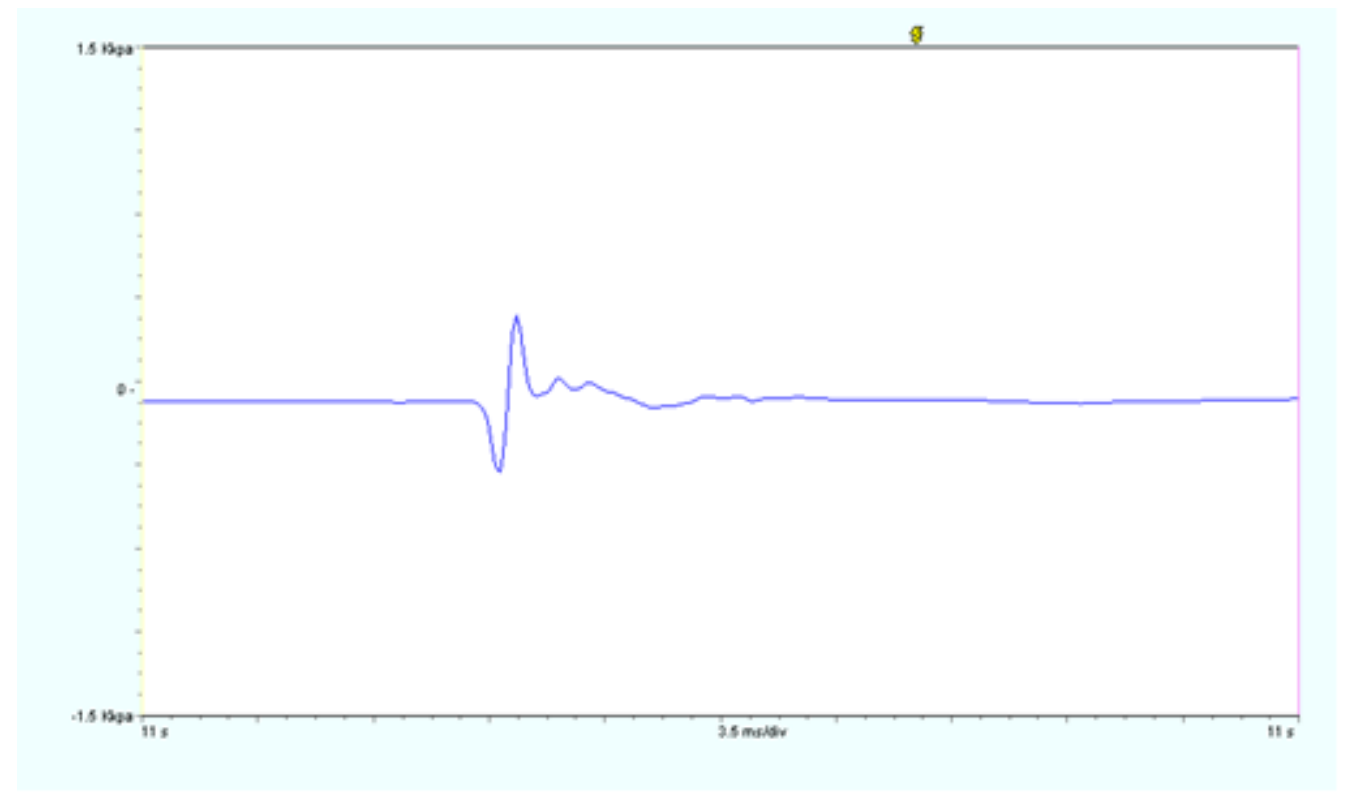

Fig.7 Offside tempus collection after hit by a peeler in the tempus

\section{Discussion}

The inland researches on temporal damage of brain biomechanics and animal experiments have found that ${ }^{[5]}$ when temporal bone stress reaches $11.2 \mathrm{MPa}$, there is only some linear fractures at certain layers of the hit offside temporal bone; when temporal bone stress reaches $15.4 \mathrm{MPa}$, there will be wale fractures or mixed types of fractures at the temporal bones and at the same time there will be pitting fractures and malpositions and so on; when temporal bone stress reaches $18.2 \mathrm{MPa}$, there will be comminuted fracture. Other correlational researches ${ }^{[6]}$ show that the fracture tolerance of the lower limbs long bone is general $125 \mathrm{MPa}$. Based on Willinger R literature ${ }^{[7]}$, we know that the yield stress of the cortical bone is $90 \mathrm{MPa}$, and that of the cancellous bone 
is $28 \mathrm{MPa}$. Through the project skull VonMises stress analysis, the slender peeler group frontal bone shows the maximum stress $236 \mathrm{MPa}$, and next is the thick peeler group 207.1 MPa, and next is the thick club group frontal bone which shows the maximum stress $107.7 \mathrm{MPa}$, and finally the slender club group frontal bone which shows the maximum stress 53.8MPa. Compared with the yield stress of the cortical bone, the thick peeler group, the slender peeler group and the thick club group all exceeds the osseous yield stress, which means the thick peeler group, the slender peeler group and the thick club group will cause plastic deformation on the skull.

Encephalic pressure peak is the response of the head to the external force load, and it is used as the important indicator to assess the degree of craniocerebral injury. Ward and so on [ ] inferred from animal, corpse experiment and finite element modelling that there exits head pressure pressure and when the pressure peak exceeds the tolerance, it will results in brain contusion and hemorrhage. The difference of encephalic pressure peak will result in the difference of the degree of injury: when encephalic pressure exeeds $235 \mathrm{kPa}$, there will be severe cerebral injury; when it is between 173 and 235 $\mathrm{kPa}$, there will be moderate cerebral injury; when it is below $173 \mathrm{kPa}$, there will be mild cerebral injury at most.

In the experiment, when the top hit was conducted, though there appeared the clinical manifestation such as bottom cerebral injury, roachback buckling, long time coma (the brainstem was shocked or contused), the encephalic pressure test result showed that when the top hit was conducted, the pressure value of the basis cranii brainstem would be positive, which wasn't in accord with the cavity theory. Because the outline of the rabbit brain is like a prolate triangle, when it was hit, the extrusion of the parietal bone and basis cranii would cause damage to the underside of the cerebrum and the diencephalon. This kind of crush injury is different from the brain crack caused by two external forces. Its formation is caused by radial overall deformation of the brain itself. When the top hit was conducted, the surrounding pressure of the brainstem rose at once. It is thus clear that even though there is no specific contusion, the brain can suffer shock and this can be seen from the long time coma and roachback arms and legs buckling after the top hit.

When the tempus hit was conducted, the pressure test result showed that the offside (hedging part) was negative, the top and basis cranii were positive. Besides, the hedging part appeared negative pressure at one moment and turned positive pressure the next moment, producing vibratility pressure change. This was in accord with the classical cavitation damage theory. Mild angiorrhexis and cerebral contusion of the offside part were thought to be caused by pressure difference. But seen from the dissection result, cerebral hemorrhage and cerebral injury mainly happened to the hit side, which was not completely in conformity with cavitation theory. The reason might be that the hit parts of the experiment were the top and tempus, hit model was accelerating injury model, after hit free motion, buffer behind occipitalia. All these factors made the relative movement between cranium and cerebrum reduced after the rabbit brain received energy. Part of the scholars also put forward that cavitation theory was fit for whole injury of endocranium only.

\section{Conclusion}

Craniocerebral injury injury site is different, resulting in various changes in intracranial pressure, and thus the mechanism of brain injury is different. 


\section{Acknowledgment}

This project was supported partially by Chongqing Science and Technology Innovation Project of Social Undertakings and Livelihood Security (cstc2015shmszx00004), China.

\section{References}

[1] D. Viano, H. VonHolst, E. Gordon, Serious brain injury from traffic related causes: priorities for primary intervention,Accid. Anal. Prev. 29 (1997) 811-816.

Reference to a book:

[2] Menon DK, Zahed C. Prediction of outcome in severetraumatic brain injury. CurrOpinCrit Care 2009;15(5):437-41.

[3] Markus Große Perdekamp, Hans-Joachim Weisser, Stefan Pollak, Annette Thierauf. Intracranial impalement with entrance site in the mandibular region: Postmortem elucidation of an accidental fall on a wooden plant stick. Forensic Science International 209 (2011) 35-40.

[4] SaurabhChattopadhyay, ChandrabhalTripathi. Skull fracture and haemorrhage pattern among fatal and nonfatal head injury assault victims - a critical analysis. J Inj Violence Res. 2010 Jun; 2(2): 99-103.

[5] Chen XW, Wang HJ, Zhao WD, Zhang MC. The biomechanics research of head with force hammer impact test. ChineseJournalof Clinical Anatomy, 2005,23(3):298-302.

[6] Beillas, P., Begeman, P C., Yang, K H.(2001)Lower limb: Advanced FE Model and New Experimental Data,45thStapp Car Crash conference San Antonio, Texas: SAE 2001-22-0022.

[7] Willinger R, BaumgartnerD, ChinnB, etal. Head tolerance limits derived from numerical replication of real world accidents. In: Proc of International IRCOBI Conference on the Biomechanics of Impacts.Montpellier:IRCOBI,2000,209-221.

[8] Ward C and Thompson R. The development of a detailed finite element brainmodel. In: Proc of 19th Stapp Car Crash Conference, SAE, Warrendale, Pennsylvania, USA, 1975. 